\title{
La frontera: confín del Estado alterado*
}

\author{
ZENIA YÉBENES ESCARDÓ**
}

\begin{abstract}
The Border: An Altered State Boundary. This article links the border, as the border of a State, to the idea of an altered State, and place the political at the heart of the psychological and the psychological at the heart of the political. An altered State produces altered conditions in the citizens who have an air of family with the psychotic crisis specially when the delirium is about the power and its violence. The difference between the two experiences (the altered State and the psychotic crisis) is played on two aspects: the relation of these frontiers to discourses and the relation of borders to secrecy.

Key words: secret, delirium, conspiracy, limit
\end{abstract}

\section{Resumen}

Este artículo vincula la frontera, como frontera de un Estado, con la idea de un Estado alterado, y sitúa lo político en el corazón de lo psicológico y lo psicológico en el corazón de lo político. Un Estado alterado produce condiciones alteradas en los ciudadanos que tienen un aire de familia con la crisis psicótica, en especial cuando el delirio es sobre el poder y su violencia. La diferencia entre las experiencias de un Estado alterado y la crisis psicótica se juega al menos en dos aspectos fundamentales: la relación de estas fronteras con los discursos y la relación de las fronteras con el secreto.

Palabras clave: secreto, delirio, conspiración, límite

\footnotetext{
* Artículo recibido el 30/05/17 y aceptado el 13/11/17.

** Universidad Autónoma Metropolitana, Unidad Cuajimalpa, Departamento de Humanidades. Av. Vasco de Quiroga núm. 4871, col. Santa Fe Cuajimalpa, Cuajimalpa, 05370, Ciudad de México <zenia.yebenes@gmail.com>.
} 
Hoy vuelvo a la frontera Otra vez he de atravesar Es el viento que me manda Que me empuja a la frontera Y que borra el camino Que detrás desaparece

Me arrastro bajo el cielo Y las nubes del invierno Es el viento que las manda $Y$ no hay nadie que las pare A veces combate despiadado A veces baile

Y a veces... nada

Hoy cruzo la frontera

Bajo el cielo

Bajo el cielo

Es el viento que me manda Bajo el cielo de acero Soy el punto negro que anda A las orillas de la suerte.

Lhasa de Sela

$\mathrm{E}$ n su cuarta acepción, según el Diccionario de la lengua española, la definición de frontera indica que ésta puede ser entendida como "confín de un Estado”. Podríamos tomar la sugerencia de Begoña Aretxaga -a quien sigo de cerca en mi aproximaciónde vincular la frontera como confín de un Estado a la idea de Estado alterado. La noción de Estado alterado pretende situar lo político en el corazón de lo psicológico y lo psicológico en el corazón de lo político (Aretxaga, 2008). Esta noción se vincula con un análisis de la subjetividad en el que la palabra sujeto hace referencia tanto a la capacidad de agencia como a la sujeción al orden social. Hablar de sujeto en este sentido cobra relevancia a la hora de reflexionar sobre el Estado y formas de ciudadanía en maneras que no serían tan evidentes si habláramos del "yo" o "la persona”. Estado alterado es entonces un tropo para referirnos a desórdenes políticos y subjetivos que nos permiten aproximarnos simultáneamente a modalidades de subjetividades (como cuando hablamos de "estados alterados de conciencia", por citar un ejemplo) y formas de vida social que reflejan el establecimiento de órdenes políticos, morales y epistémicos a través de un estado de violencia que -paradójicamente-reproduce el desorden. Por Estado alterado, en este segundo sentido que acabamos de describir, entendemos

...un Estado en el que se produce una cierta dislocación y a menudo un desorden violento de cosas. El orden lógico cartesiano de pensamiento no funciona bien $\mathrm{y}$, sin embargo, tampoco deja de funcionar. Es un Estado en el que las cosas están un poco fuera de donde deberían estar y a veces un mucho, de forma que el estado de las cosas parece una locura. Y es a menudo a través del tropo de la locura que se da cuenta de estos Estados alterados [Aretxaga, 2008: 44].

Imaginado y fetichizado a veces como actor, el Estado alterado puede infligir ansiedad extrema y producir efectos traumáticos (o estados alterados) en los sujetos. Veamos un ejemplo. En un estado alterado particular, como es la psicosis, la primera fase del brote llamada trema se inaugura con un estado anticipatorio de un temor radical. Trema se caracteriza por tres aspectos: "la irrealidad, a través de la cual el mundo queda vacío de cualquier sentimiento o autenticidad; el mero Ser, en el cual el hecho bruto de la existencia desafía al discurso o la experiencia, y la fragmentación, en la que detalles o partes saturan el todo" (Sass, 1994: 50). Asimismo, en los sujetos que han sufrido un trauma severo debido a la violencia política extrema de un Estado alterado, lo que Michael Taussig (1987) describe como cultura del terror,

los síntomas se reúnen en tres categorías. El estado de alerta permanente $[\ldots]$ como respuesta a un peligro extremo [...] La intrusión [...] que incluye fragmentos vividos del evento traumático con escasa o nula elaboración imaginativa $[. .$.$] La retracción [...] que implica la desper-$ sonalización, la desrealización y la distorsión [Herman, 1992: 32-43].

Es importante aclarar que no estoy diciendo que una experiencia de violencia política extrema del Estado alterado sea exactamente lo mismo que un estado alterado como una crisis psicótica, aunque a veces esta relación se hace más evidente cuando los pacientes ${ }^{1}$ deliran con acontecimientos álgidos de la historia social.

En mi trabajo de archivo sobre la historia de la demencia precoz y la esquizofrenia en México, me salió al paso P. J. H., de 27 años, natural de Chihuahua, soltero, ingeniero de minas, que había ingresado al

1 Utilizo la palabra "paciente" porque a través de ella pretendo señalar el carácter irremisiblemente medicalizado con el que hoy concebimos y gestionamos a la locura, y apuntar simultáneamente a la condición, mucho más inasible, y que escapa a la idea de medicalización, de aquel que sufre un pathos. 
sanatorio Rafael Lavista en 1924. Declaraba que "era perseguido por el gobierno pues lo tomaban como conspirador en la Revolución y lo habían acusado de tal modo que no tenía salvación posible. Estaba condenado a ser fusilado y esperaba que de un momento a otro fueran por él". Si se le ofrecía alguna cosa, si se le invitaba a escribir a su familia, contestaba siempre que todo era inútil, que ya no podía desear nada, puesto que "lo habían arruinado" y que "se apresuraran a acabar con él para no hacerlo sufrir ya”. Retraído, desconfiado, se ponía de rodillas y en oración por largas horas, se alimentaba poco y no dormía. Al final, tras varios meses de permanecer en la misma postura, su aspecto era el de un autómata movido por resortes (Dávila, 1925: 133-134).

Mis reflexiones en estas páginas se articulan alrededor de una investigación antropológica que tuvo lugar en la Ciudad de México entre 2008 y 2011 y que, entre otras cosas, produjo un trabajo ya publicado (Yébenes, 2014). El eje de dicha investigación giró en torno a los talleres de lectura y escritura para personas diagnosticadas de esquizofrenia. Gracias a $\mathrm{P},{ }^{2}$ un amigo que trabaja en un centro de día de atención a la salud mental en un hospital al sur de la Ciudad de México, el primero de los talleres se llevó a cabo en el anexo de un salón parroquial. Los demás los impartí, a lo largo del tiempo y, a medida que corrió la voz, en diferentes lugares y con distintos psicoterapeutas. El hecho de que mi contacto con los pacientes no se desarrollara dentro de un marco institucional, sino en espacios más o menos "improvisados”, y de que acudieran o dejaran de acudir por su propia voluntad, fueron algunas de las peculiaridades que permearon mi trato con la locura. La carencia de hilo narrativo en el taller era lo habitual. A veces asistía una persona, otras veces diez, de las que sólo volvería a ver a dos. Se realizaban dos veces a la semana y duraban una hora. En ocasiones leíamos en voz alta, les proponía ejercicios de escritura creativa, o vincular un texto con alguna imagen... A veces funcionaba, otras no. Había quien a los 20 minutos anunciaba: "Ya es hora de irse”, o quien seguía sentado escribiendo hora y media después. Los asistentes al taller eran todos jóvenes, entre los 18 y los veintitantos años, procedían de sectores medios y populares y habían sido recientemente diagnosticados de esquizofrenia. Llegaban porque sus

psicoterapeutas les habían hablado de esta actividad de lectoescritura que parecía, en cierto modo, atraer su curiosidad. La mayoría estudiaba o trabajaba hasta que acaeció el primer brote psicótico que supuso el parteaguas y que a menudo era descrito como la irrupción de un quiebre violento: "Yo era como todos mis hermanos -escribe J- pero me cayeron encima esos seres y me atravesó un rayo" (Yébenes, 2014: 18-19).

Como habremos de ver, la catástrofe social de los Estados alterados produce condiciones perturbadas en los sujetos que tienen un aire de familia ${ }^{3}$ con la crisis psicótica. Un aire de familia que queda más claro cuando el delirio versa sobre el poder y su violencia. En las experiencias de los Estados alterados y la crisis psicótica el tejido social, literalmente, se desteje. Este aire de familia sin embargo supone asimismo destacar las diferencias. La frontera es el confín de un Estado.
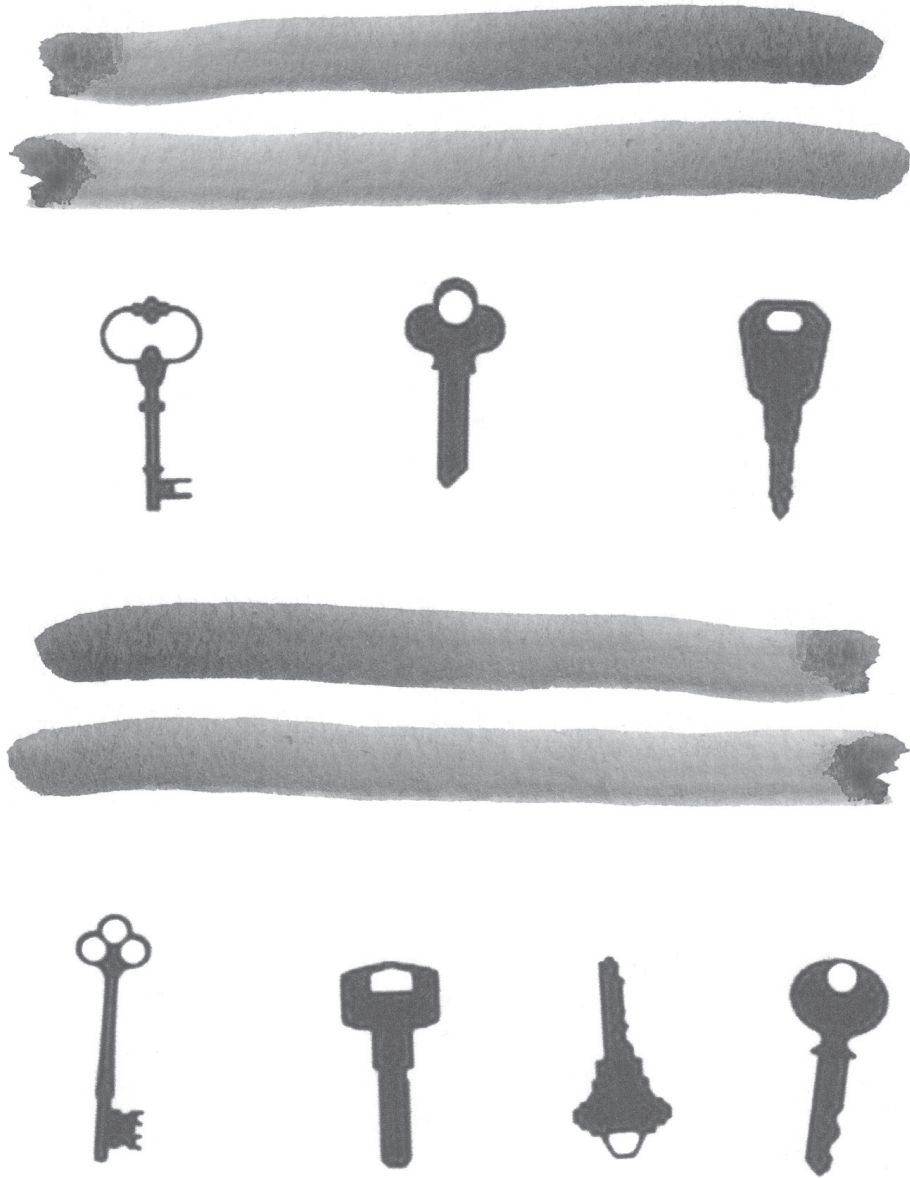

2 He protegido la identidad de los pacientes (del presente o del pasado) que se citan en estas páginas, así como la de los psiquiatras y psicoterapeutas que así me lo solicitaron y que, al igual que los pacientes a los que acompañé, estuvieron informados de mi intención de llevar a cabo esta investigación. En el caso de Rubén F, el pseudónimo fue elegido por él mismo.

3 Wittgenstein rechaza la existencia de esencias en la realidad, las cosas sólo tienen "parecidos de familia": no existe la esencia, no existe una propiedad, ni mucho menos un conjunto de propiedades, que deba estar presente en todas y cada una de las cosas para poder hacerlas parte de la misma clase (Wittgenstein, 1988, § 67: 87 y 89). 
Un Estado alterado es aquel que precisamente no dibuja con claridad sus límites y produce ansiedad, terror y una incertidumbre radical (estados alterados) en sus ciudadanos. Ante este terror y esta incertidumbre, lo que observamos en el campo social es el intento de restablecer algún tipo de frontera que delimite poderes que de otra forma se perciben omnipresentes. La crisis psicótica es un estado alterado en el que, ante un terror y una incertidumbre radicalmente amenazadores, se vuelve asimismo imprescindible el restablecimiento de fronteras. La diferencia entre ambas experiencias se juega, al menos, en torno a dos aspectos fundamentales: la relación de estas fronteras con los discursos y la relación de las fronteras con el secreto. Veámoslo más despacio.

\section{Discursos de frontera I: teorías de la conspiración}

\author{
Es el viento que me manda \\ Que me empuja a la frontera \\ Y que borra el camino \\ Que detrás desaparece.
}

Pese a las transformaciones que ha sufrido en la era de la globalización, la figura del Estado está lejos de haber desaparecido. Es cierto que, en el caso nacional, a partir de 1982, el modelo de industrialización consolidado en los regímenes posrevolucionarios se colapsó, dando paso al neoliberalismo tecnocrático. En 1992, la tendencia a la apertura al mercado mundial de economías antes protegidas llevó al gobierno mexicano a revocar las leyes de reforma agraria; dos años después entró en vigor el Tratado de Libre Comercio de América del Norte, al que seguirían más. Aunque las operaciones que habitualmente llamamos estatales sobrepasan los límites del Estado-nación y parecen ser ejercidas por otros agentes, como el pragmatismo del mercado desregulado regido por la mano invisible de la ley de la libre oferta y demanda de los monopolios informativos, las organizaciones transnacionales no gubernamentales, corporaciones privadas o los grupos de narcotraficantes, el Estado ha exhibido una tenacidad y adaptabilidad que debe destacarse. Ello se hace evidente no sólo al mostrar la manera casual en la que por lo común nos referimos a la entidad el Estado como si fuera un ser en sí mismo, animado con voluntad y entendimiento propios, sino también al comprobar los frecuentes indicios de exasperación que provoca el aura de la E mayúscula. El Leviatán de Hobbes, en definitiva, es mítico y también terriblemente verdadero:
El Estado, entidad abstracta a la que creemos con Ser, especie asombrosa de cosa con fuerza vital autónoma, trascendente por encima de los meros mortales [...] totalidad inventada de artificio materializado y en cuya insuficiencia desdichada [...] colocamos nuestra alma. De ahí la E mayúscula del Estado [Taussig, 1997: 3].

Philip Abrams subraya asimismo este carácter ficcional en una forma a la vez más esclarecedora y más compleja:

La dificultad de estudiar el Estado reside en el hecho de que el Estado como estructura o sujeto político unificado no existe; es una ilusión colectiva, la reificación de una idea que enmascara las relaciones de poder bajo el disfraz del interés público. El Estado no es la realidad que se encuentra detrás de la máscara de la práctica política. Él mismo es la máscara que nos impide ver la realidad de la práctica política [...] comienza su vida como un constructo implícito; luego es reificado, como la res publica, nada menos que la reificación pública, y adquiere una identidad claramente simbólica que progresivamente se divorcia de la práctica y se convierte en un relato ilusorio de la misma. La función ideológica llega al punto en el que conservadores y radicales creen que su actuación no se dirige de unos a otros sino al Estado. Este mundo de ilusión prevalece [Abrams, 1998: 58].

A este respecto, lo primero que hay que constatar es que, investido con una suerte de aura, persiste como presencia crucial, una pantalla en la que se proyectan los anhelos y temores de los ciudadanos: se pide al Estado, se teme al Estado, se solicita protección al Estado, se lamenta su fracaso, y se añora su fortaleza. Nos encontramos, a la postre, ante el poder espectral de una ficción. En efecto, si bien la lógica neoliberal de la globalización está erosionando las funciones clásicas del Estado weberiano, por otra parte, estimulados en cierto modo por la globalización, se están creando más y más Estados, y el deseo de las naciones por poseer su Estado propio es más intenso que nunca (Aretxaga, 2005: 255-268). En los márgenes de la política y en el ámbito local, los encuentros con el Estado se perciben a nivel de piel, a través del encuentro con miembros de los cuerpos de seguridad nacional, cuya presencia invade el espacio cotidiano. Este encuentro en el nivel local puede producirse bajo la forma discursiva de su identificación con la corrupción, la ambivalencia o el abandono de una ciudadanía que se siente indefensa (Gupta, 1995). Ello acaece cuando quien funge como Estado (el ejército, la policía, los monopolios privados, los narcotraficantes o los grupos guerrilleros) es precisamente lo que parece estar en cuestión. 
Frente a la narrativa de un Estado sólido que coexiste con un discurso nacionalista de ciudadanía, se halla asimismo la narrativa del Estado fallido. Inmersos en esta dinámica, cuando los sujetos perciben que el orden social es en sí mismo inconsistente, la fantasía es un intento de reconstituir su consistencia (Aretxaga, 2005: 255-268). Esto tiene por lo menos una consecuencia: se postula la existencia de un gran otro oculto detrás de la textura social explícita en una proliferación de teorías de la conspiración. Debe recordarse que estas teorías son aquellas que consideran que todo evento social es consecuencia de la maquinación de una fuerza superior y, a menudo, secreta. Son discursos cerrados y autoconfirmatorios. Cuando se intenta refutar la teoría de la conspiración apelando a lo inverosímil de la trama planteada o señalar que la conspiración implica una relación casi perfecta entre intención y consecuencia de la acción, mientras que el sentido común nos dice que esa relación no siempre es la esperada, estas apelaciones hacen poca mella en una forma retórica cerrada que con facilidad los clasifica como parte de la conspiración que es denunciada (Popper, 2000).

En "El hechicero y su magia”, Lévi-Strauss aclara:

[Las] actitudes muy imprecisas y no elaboradas que, para cada uno de nosotros, poseen el carácter de experiencias [...] siguen siendo intelectualmente informes y afectivamente intolerables, a menos que se incorpore a ellas tal o cual esquema flotante en la cultura del grupo, cuya asimilación es lo único que permite objetivar estados subjetivos, formular impresiones informulables e integrar en un sistema experiencias inarticuladas [1995: 199].

Entre los zuñi de Nuevo México, por ejemplo, un muchacho es acusado de brujería y obligado a confesar. Tras haberse declarado inocente en un principio y no resultar del todo convincente su primera confesión, ha de realizar una segunda, que sea creíble para el grupo. Para ello, debe contar una historia que contribuya a corroborar la acusación:

Puede advertirse ante todo que, perseguido por hechicería y amenazado así con la pena capital, el acusado no gana la absolución disculpándose, sino reivindicando su supuesto crimen; más aún refuerza su causa presentando versiones sucesivas cada una de las cuales es más rica, más llena de detalles (y en principio, entonces, más culpable) que la precedente [Lévi-Strauss, 1995: 200].
El relato lo va atrapando a él mismo y a sus oyentes, de manera que en el proceso se transforma

...de culpable, en colaborador de la acusación. Gracias a él, la hechicería y las ideas a ella asociadas escapan a su penoso modo de existencia en la conciencia, como conjunto difuso de sentimientos y representaciones mal formulados, para encarnarse en ser de experiencia [LéviStrauss, 1995: 201].

Lévi-Strauss advierte que, aunque el destino del brujo en la sociedad zuñi es ser ajusticiado, el muchacho es perdonado porque "aporta al grupo una satisfacción en la verdad, infinitamente más densa y más rica que la satisfacción en la justicia que hubiera procurado su ejecución" (Lévi-Strauss, 1995: 201). Gracias a la descripción de Matilda Coxe Stevenson -en la que él mismo se apoya-sabemos, sin embargo, que el muchacho estuvo a punto de ser asesinado y que fue la autoridad colonial quien lo impidió. También sabemos que los brujos continuaron siendo ejecutados entre los zuñi. ${ }^{4}$

Lo que Lévi-Strauss desea subrayar con su aseveración es que, al aceptar la acusación de brujería, el muchacho permite articular lo que hasta entonces es sólo una sospecha intelectualmente informe y afectivamente intolerable, y garantizar así el restablecimiento del orden social. Para Lévi-Strauss se trata de restaurar la coherencia perdida cuando la vida social se ve afectada por una impresión informulable. Podríamos pensar en las teorías de la conspiración desde esta lectura de Lévi-Strauss con la condición de asumir que son discursos que indican que el mundo social depende, no de la comunión perfecta "inmanente" o de una "satisfacción en la verdad", sino de las imperfecciones de la comunicación (Nancy, 2001: 30-35). Por ejemplo, hay quienes sostienen que la ilusión mistificadora sobre un centro de poder llamado Estado podría ser desenmascarada en la emergencia de la realidad de las relaciones dispares que lo sustentan. Pese a ello, contemplar la interioridad laberíntica del ser del Estado no necesariamente disipa su poder mistificador. Al contrario, tal poder parece aumentar con la revelación del escándalo, y provocar una proliferación infinita de discursos sobre él. No es tanto la identificación con la "satisfacción en la verdad" lo que regula el circuito "normal" diario de la comunidad, sino más bien la necesidad de establecer fronteras que permitan dibujar las posiciones dinámicas que se

4 Matilda Coxe Stevenson era la esposa del jefe del Buró de Etnología Americana que llevó a cabo la expedición entre los zuñi; fue rival acérrima de su compañero de expedición Frank Cushing, a quien en algunos ámbitos se le reconoce haber sido quien iniciara -no Malinowski- la práctica de observación participante. Cf. Stevenson (1904). 
ocupan en el campo social y conjurar la amenaza de la indeterminación y la incertidumbre. Esta conjura no es nunca satisfactoria en su totalidad, de ahí la proliferación y el desplazamiento de los rumores y los discursos de la conspiración. Ahora bien, como he señalado con anterioridad, la vida de la comunidad depende precisamente de esta insatisfacción. Es ella la que nos hace dirigirnos a los otros buscando un suelo común bajo la forma del "se dice". Los Estados alterados en los que se produce una cierta dislocación y a menudo un desorden violento de cosas nos permiten contemplar así dos operaciones en la teoría de la conspiración que se relacionan con la posibilidad de hacer comunidad.

Por un lado, "el viento empuja a la frontera". Esto es, en las vicisitudes y las contingencias en las cuales se produce el campo social hay la necesidad de fronteras que brinden ciertas coordenadas (en este caso, la de delimitar el confín del Estado adjudicándole su funcionamiento a un grupo o poder secreto que permita distinguir entre el lugar de un ellos y el de un nosotros que posibilite cierta delimitación). Por otro lado, se "borra el camino que detrás desaparece", es decir, estas fronteras han de ser renegociadas y recreadas de manera continua para que una comunidad sea tal. La frontera es un horizonte necesario para impedir que, en ausencia de toda articulación entre las relaciones sociales, se asista a una implosión de lo social, a una ausencia de todo punto de referencia. La necesidad de su articulación debe ser, no obstante, constantemente recreada y renegociada, y no hay punto final en el que el equilibrio sea alcanzado en definitiva. Esta imposibilidad es constitutiva de la vida social. Sin la recreación y la renegociación, la vida social, simplemente, no existiría.

\section{Discursos de frontera II: la certeza delirante}

Es el viento que las manda Y no hay nadie que las pare A veces combate despiadado A veces baile Y a veces... nada.

En la sociedad mexicana contemporánea existe la dificultad de medir las interacciones entre la vasta anatomía de poderes sociales que regulariza la vida cotidiana y la decisión soberana del Estado para definir la arena política, al imponer y actuar sobre una distinción del enemigo interno de la nación. La indistinción entre la decisión soberana de matar y la regulación administrativa del orden parece requerir de una reflexión conceptual y práctica del mero hecho de la soberanía. Jacques Derrida ha advertido sobre cómo, en la actualidad, cuando la idea de soberanía nacional está siendo puesta a prueba, el Estado exacerba su presencia autoritaria:

Dicha prueba demuestra, más o mejor que nunca (pues la cosa no viene de ayer) a la vez la fragilidad de la soberanía del Estado-nación, su precariedad, el principio de ruina que lo trabaja y [...] la denegación crispada, con frecuencia asesina, de sus sobresaltos y coletazos de agonizante [Derrida, 2005: 184].

Hay que dar cuenta de las tentativas, siempre parciales y recurrentes, del Estado mexicano por distinguirse a sí mismo frente a la sociedad, de la amenaza y la experiencia de la violencia, el desorden o la ilegalidad. La militarización del país para erradicar los cárteles, armados del narcotráfico ha supuesto que no haya una distinción entre las fuerzas del orden y las que no lo son. Aparentemente, hay una frontera entre civiles y militares porque el ejército va uniformado y asevera hallarse del lado de la ley. Pero los cárteles y la policía pueden estar coludidos, los militares son suplidos por grupos paramilitares de defensa, y la fuerza civil está mejor armada que la militar. En los niveles tecnológico y administrativo, la diferencia entre los uniformados y los no uniformados, entre la soberanía y la contrasoberanía, deja de ser relevante. La guerra contra el narcotráfico implica una enemistad abierta entre el Estado y los cárteles, porque éstos suponen un reto directo a su sutura del territorio, de la población y el mercado dentro del orden jurídico reconocido. Sin embargo, la ideología de unos y otros es la misma. Los cárteles expresan, de forma cruda, los principios de la propiedad privada y de la monopolización individual de la riqueza. Lo que se hubiera querido negar, y cada vez resulta más difícil, es que nuestra dificultad para distinguir entre unos y otros proviene de que no hablamos de un conflicto ideológico, porque la ideología de unos y de otros no se diferencia. En este sentido, la guerra contra el narcotráfico es una guerra en la que el crimen ha sido engendrado "en familia".

$\mathrm{Si}$ bien entre los asistentes a los talleres para pacientes de esquizofrenia era frecuente el recurso de las teorías de la conspiración, quizá en ningún caso tan evidente y notorio como en el de Rubén F intervenían, de manera particularmente acuciante, las noticias que cimbraban la realidad nacional que involucraban al ejército y a los narcotraficantes, y que él seguía con detenimiento día a día. Tanto en los talleres como en los encuentros continuados que tuve 
con Rubén, decidí no utilizar grabadora. Llevaba mi libreta y tomaba notas camino a casa. En ese mismo tenor, nunca realicé entrevistas en sentido estricto. Traté de entablar relaciones -ir a tomar café, al cine, dar un paseo- y de privilegiar los elementos que él mismo subraya en sus narrativas y en sus prácticas. Rubén F, de 26 años, vivía con sus padres y con sus dos hermanos. En un inicio le habían diagnosticado esquizofrenia indiferenciada, pero el diagnóstico final fue esquizofrenia paranoide. Para él era absolutamente imperioso distinguir entre los que estaban con él y contra él, entre quienes querían que permaneciera a salvo y quienes, en alianza con fuerzas de seguridad nacionales e internacionales, que se vinculaban con sectas y cultos misteriosos, querían destruirlo: "Hay que descifrar porque la precisión en el análisis es absolutamente necesaria”, advertía. Para Rubén, en el centro de la Ciudad de México se anudaba una red de túneles subterráneos que recorrían todo el país, donde "fuerzas oscuras" llevaban a cabo matanzas en las cuales se asesinaba -a través de prácticas ligadas con cultos rituales- a un conjunto indeterminado de personas que nunca identificaba de forma individual. Como miembros de estas "fuerzas oscuras", cuyo poder leía en las noticias cotidianas de los medios de comunicación, señalaba a militares, políticos, narcotraficantes, actores, actrices y policías, aunque cualquiera podría trabajar a su favor y ser, como él decía, "ayudante del mal".

Las teorías de la conspiración permiten establecer fronteras (siempre inestables dada su proliferación) en las cuales el grupo posee la certeza que no tiene el sujeto. De ahí la importancia del "se dice”. Esa certeza se convierte, así, en la causa colectiva, en argumento de verdad. Los sujetos se esfuerzan y se empeñan en convencer, pues requieren al grupo para alimentar su creencia, sustentarla, en definitiva, creérsela en la misma proporción que les fustiga la duda; sin
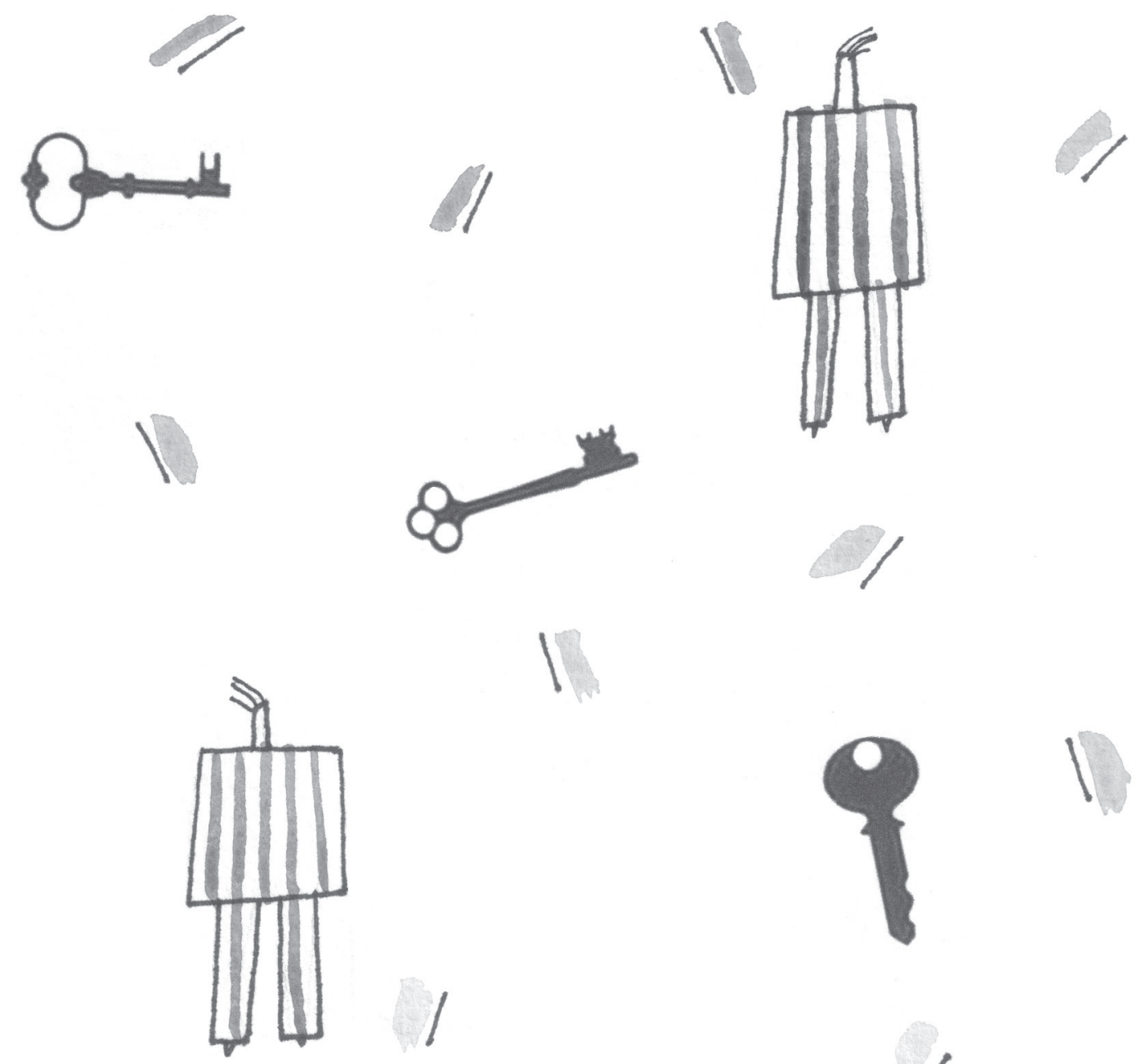
embargo, para Rubén, la certeza colectiva no era suficiente. Parecía sufrir "un sentimiento de inconsistencia y de inseguridad, que le impulsaba instintivamente a buscar un punto sólido en qué afirmarse y aferrarse" (Álvarez, 1996: 276). Este punto sólido se transformaba en una certeza "sin necesitar testigos que la avalasen, ni razonamientos que la fundamentasen, ni verificaciones que la sostuviesen" (Álvarez, 1996: 270). Es lo que se conoce con el nombre de certeza delirante:

Más apropiado aún que el término "creencia delirante" o "convicción delirante", es "certeza”, sin más calificativos, pues como tal, la certeza nos parece propiedad exclusiva del psicótico. Decir esto exige dos aclaraciones: primera, que la certeza no tiene grados, y segunda, diferenciar la certeza de las creencias por más apasionadas que sean, que sí tienen graduaciones. En los heterogéneos dominios de las creencias, de las que todos participamos, se aprecia una radical oposición con la certeza. Mientras el psicótico está capturado en su certeza, sin necesitar testigos que la avalen, ni razonamientos que la fundamenten, ni verificaciones que la sostengan, el creyente se esfuerza y se empeña, a veces hasta aburrir, en convencer, pues tras tanta insistencia apologética se encubre siempre un pliegue de duda [Álvarez, 1996: 270].

La certeza delirante le permitía a Rubén establecer una frontera de la amenaza de las relaciones de poder en un campo social que le parecía radicalmente intrusivo y amenazador. Ahora bien, esta respuesta-a diferencia de lo que sucede en las teorías de la conspiraciónno estaba en los otros sino en él mismo. La frontera no era renegociada, ni recreada con otros porque el "se dice", al que hemos hecho referencia, introducía para él un grado de incertidumbre que no era capaz soportar. La certeza delirante es radicalmente solitaria, no puede ser apropiada, tematizada o discutida por los demás porque hay una desconfianza tajante en cualquier suelo que se pretenda común. Fuerzas sobrenaturales superiores habían hecho de Rubén un ser del todo distinto, un "predestinado": "Me han elegido para descifrar, por eso puedo obtener energía con sólo tocar el piso y adivinar y predecir el futuro", me advertía. Había en él una pérdida de confianza absoluta en los otros -que no era un mero ejercicio reflexivo, sino que afectaba en extremo el meollo mismo de la subjetividad-. La verdad como certeza o causa colectiva no bastaba, porque él entrevía su carácter de producción social, la pluralidad de discursos que la atravesaban, "a veces baile y a veces nada”. La certeza delirante garantizaba su autoridad en una revelación estrictamente singular que provenía de una instancia superior. "La verdad que me comunican es la VERDAD con mayúsculas -me dijo un día mientras leíamos el periódico-, no las opiniones, que es lo que viene aquí”.

\section{La frontera y el secreto I: el secreto público}

\author{
Hoy cruzo la frontera \\ Bajo el cielo \\ Bajo el cielo.
}

\section{Escribe Wendy Brown:}

\begin{abstract}
La paradoja de lo que llamamos el Estado es que es al mismo tiempo un ensamble de relaciones de poder y un vehículo de dominación masiva incoherente y multifacético. A pesar de la tendencia casi inevitable de hablar del Estado como una cosa, el dominio que llamamos el Estado no es una cosa, ni un sistema ni un sujeto, sino un terreno significativamente disperso de poderes y técnicas, un conjunto de discursos, reglas y prácticas que cohabitan en la limitación, la tensión y la relación, de manera a menudo contradictoria [1995: 174].
\end{abstract}

Lo interesante aquí es que no sólo la gente imagina al Estado, sino que el Estado mismo, en sus múltiples materializaciones, promulga sus propias fantasías. Este reflejo dinámico entre la relación imaginaria de aquellos que encarnan el Estado y quienes se topan con sus efectos en la vida diaria, sugiere la presencia de mecanismos psíquicos del poder (Butler, 2001), que producen y reproducen el Estado como objeto de temor y de repulsa, de apego y de identificación, como un poder evasivo, invencible, impotente, alguna vez presente, o enormemente poderoso. Hoy, que las funciones del Estado, lejos de desaparecer, son además reclamadas por distintos actores nacionales y transnacionales, el principio de autoridad, la necesidad de eliminar el exceso social, de garantizar los signos y los valores a través de nuevos tipos de redes, ha de materializarse de manera visible en el cuerpo de los ciudadanos. El cuerpo se convierte en fuente de verificación y de materialización de la autoridad simbólica de las instituciones y los hechos sociales, algo que se pone precisamente de relieve:

En momentos particulares, cuando hay dentro de la sociedad una crisis de creencia, es decir, cuando alguna idea central, ideología o constructo cultural ha cesado de suscitar la creencia de la población, ya sea porque es manifiestamente ficticia o porque queda desposeída de sus formas ordinarias de substanciación, la punzante 
materialidad del cuerpo humano será prestada para otorgar a ese constructo cultural el aura de realidad y certidumbre [Scarry, 1985: 14].

La idea de que el cuerpo, en tanto que apropiado socialmente, está investido de más significantes que los puramente "biológicos" o "naturales" se dispersa en la soberanía del cuerpo de la nación a través de los cuerpos de los ciudadanos que nunca son meros cuerpos, sino signos de algo más que significa en relaciones distributivas y diferenciadas de poder, que ahora hay que monitorear, regularizar y controlar (Santner, 2011). Lo que está en juego no son tan sólo las formas de manejo de cuerpos y poblaciones, sino el exceso de los cuerpos y de las intimidades que son el resultado de aquellas técnicas de manejo, y que producen efectos en los procesos de constitución subjetiva. Las ideologías de la diferencia toman la forma de signos corporales diacríticos que abastecen la obsesión de hacer legibles los cuerpos considerados amenazadores en potencia. Estas prácticas intensas de legibilidad a menudo generan más opacidad. Los sujetos trabajan con estereotipos, de modo que se puede ver todo y nada al mismo tiempo.

Los cuestionamientos apuntan al interrogante de si el Estado no es necesariamente el producto de tecnologías racionales de control, sino de un exceso que sobrepasa cualquier racionalidad funcional. Lo que articula el exceso es la fantasía (la fantasía del control total, la fantasía de la apropiación del otro), que aparece como un componente principal de la vida política y un factor clave que estructura las relaciones de poder. La fantasía no quiere señalar aquí una construcción puramente ilusoria, sino una forma de realidad que se autoriza a sí misma, una escena cuya estructura atraviesa el límite entre lo consciente y lo inconsciente (Žižek, 2007: 11 -39). La fantasía, en este sentido, pertenece a lo "objetivamente subjetivo". No se opone a la realidad social, antes bien, constituye su "pegamento psíquico". La representación del Estado como el ojo omnisciente que nos lee y que se esconde bajo un cielo y parece tener la posibilidad de someternos a escrutinio. La representación de una omnisciencia de algún tipo detrás de la práctica política se sustenta en el aura de secreto que parece rodearla.

Este secreto es público, es "generalmente sabido, pero no puede ser articulado, es, de hecho, un secreto tan público, que incluso la apariencia de conocimiento del secreto ha de ser evitada: 'la gente sabe qué es lo que no debe saber"' (Taussig, 1999: 131). Sergio González Rodríguez, al referirse al entramado del Estado-nación en México, lo define así:
Una construcción ominosa, suerte de ramal del drenaje profundo que, en lo simbólico, amenaza a toda la sociedad y quiere instalarse en la permanencia más anestésica con su mandato inaceptable: no te metas en lo que no te corresponde [González Rodríguez, 2009: 162].

El ocultamiento involucrado tiene el carácter de una prohibición: "No debes hacer saber que sabes X", pero en su corazón hay una simulación: "incluso cuando $\mathrm{X}$ sea sabido por todos has de actuar y pensar como si X no pudiera ser sabido". Desde esta perspectiva del "saber qué no saber", los actos de violencia que acaecen en territorio nacional se comportan como una lengua capaz de funcionar con eficacia porque de algún modo el código se conoce, aun cuando no se participe de modo directo en la acción enunciativa. Este secreto público permite el establecimiento de una frontera a través de la negación. Se sabe qué es lo que NO se ha de saber. Al ser un secreto tan público, que no puede ser articulado, es un secreto que me vincula con otros y que produce formas alteradas de comunidad a partir de un NO saber: nos hallamos ante "la afirmación de un caos redituable [...] basado en el secreto compartido [...] y una comunidad centrífuga que alcanza toda la escala social y asedia el ámbito familiar" (González Rodríguez, 2009: 163).

\section{La frontera y el secreto II: el secreto de lo privado}

Soy el punto negro que anda a las orillas de la suerte.

Los relatos de los pacientes psicóticos sobre su experiencia hablan de un exceso de sensaciones y significados que escapan al orden y la coherencia, y de una confusión de fronteras que crea un profundo sentimiento de desdibujamiento e incertidumbre. A la vez, la cualidad enigmática e incierta de la experiencia puede abrir abismos subjetivos que paralizan y congelan la vida del paciente. Hemos contemplado cómo en el marco de la guerra contra el narcotráfico la violencia de los aparatos de seguridad en México se transforma en vigilancia de los propios ciudadanos, en una mirada que también podríamos considerar paranoica, que restringe los derechos civiles y que esparce el terror a través del campo social. Las fuerzas de seguridad y los narcotraficantes se vuelven alucinantes y espectrales porque ocupan todo; están en todas partes incluso donde no están, como puso en evidencia la realización de diversos operativos del Ejército y la Marina buscando de manera infructuosa a los Zetas 
en el entonces Distrito Federal, y la sospecha de una creciente militarización en la Ciudad de México que alcanzaba una extensión inusitada (cf. Gómez, 2011; Bolaños y Pantoja, 2011; Martínez, 2011).

Para Rubén, la sensación de confusión e incertidumbre suponía un desdibujamiento de los límites en los que no sólo no se sabía quién era quién, sino que los otros eran capaces de manipular su cerebro, de leer todos sus pensamientos, robárselos o insertar otros nuevos. La cualidad enigmática de esa experiencia hacía que él concediera al escenario político nacional dimensiones apocalípticas y escatológicas. Si para el Estado las ideologías de la diferencia toman la forma de signos corporales diacríticos que abastecen la obsesión de hacer legibles los cuerpos considerados potencialmente amenazadores, Rubén se concebía a sí mismo como un panóptico totalmente transparente que fuerzas militares y poderosas pueden en cualquier momento intervenir. En sus crisis más álgidas insistía en su necesidad de aislamiento y llegaba a encerrarse en su habitación tapiando incluso las ventanas y no dejando entrar a nadie.

El aislamiento en la psicosis constituye lo que Piera Aulagnier denomina una zona de secreto. Es decir, el establecimiento de una frontera que señale una inaccesibilidad ante lo que se percibe como un desdibujamiento y una intrusión insoportable de los otros. Esta zona de secreto permite construir un espacio que posibilita restaurar los límites entre el interior. Es el equivalente a una "caja negra", "punto negro" diríamos nosotros. Un "espacio vacío" indispensable para efectuar distancia y poder delimitar (Aulagnier, 1991). La psicosis revela la función destructiva de lo negativo cuando los límites se ven atacados y las representaciones se disuelven. La zona de secreto es un intento de restablecimiento.

Esta zona de secreto cumple una función de individuación. El restablecimiento de los límites y las fronteras se presenta como algo absolutamente ineludible en la esquizofrenia en la que, para el paciente, no se ha logrado la intimidad imprescindible para mantener a resguardo sus pensamientos, razón por la cual cree que cualquiera se entera de ellos o se los impone de manera arbitraria. Eso cuando no se los roban o divulgan por cualquier medio. Rubén F me contaba: "Hoy fui a desayunar con mi mamá y no estaba el mesero que está siempre. Me miró y luego le dijo algo de mí al otro mesero". "Sé que es policía. Hay como un juego en la forma de mirarme y sé que quieren atraparme". "Me preocupa porque tienen acceso a mi mente y pueden manipular y cambiar todo lo que pienso". Cuando el sujeto se contempla a sí mismo como un escenario vacío en el que pensamientos, acciones y sentimientos tienen lugar como fuerzas totalmente exteriores que le imponen sus enemigos, es necesario el restablecimiento de una frontera que le permita individuarse, ser él, distinguirse de otros.

Cualquier reserva o simple circunspección que abriguen los psicóticos no solo no debe ser atacada, sino que es necesario potenciarla en la medida de lo posible [...] Debemos tener presente que [...] en cuanto se toca una zona delicada o se transforma en un sentimiento demasiado íntimo y personal, el psicótico no sabe encajarlo y se ve obligado a reaccionar: destruye la relación, se aísla, o se cree perseguido y vigilado. Cualquier muestra de intimidad que desborde sus límites supone desgarrar su velo de privacidad y someterle a la transparencia inerme que lo ha enloquecido [Colina, 2013: 16].

Salvaguardar el secreto supone la posibilidad de instituir fronteras que permitan su existencia como un sujeto cuyos pensamientos, sentimientos y emociones reconoce como propios. En los Estados alterados el secreto público posibilita el establecimiento de una frontera a partir de lo que se sabe que NO hay que saber. Una frontera que supone la emergencia de una comunidad alterada por un NO saber compartido. En los estados alterados de la psicosis el secreto remite también a una frontera, pero no a una que pueda ser compartida por otros. El secreto de la psicosis es el secreto de lo privado, de lo que no es compartido con ningún otro porque eso es precisamente lo que se ve perturbado y fragilizado en la experiencia psicótica y aquello que se intenta, radicalmente, proteger.

\section{Reflexiones finales: para una antropología de la frontera}

Hoy vuelvo a la frontera Otra vez he de atravesar.

Estas páginas iniciaban con la acepción del Diccionario de la lengua española según el cual la frontera puede ser entendida como "confín de un Estado". Los Estados alterados producen estados alterados en los sujetos y formas inéditas de hacer comunidad. Aquí he señalado dos. La teoría de la conspiración, que permite fronteras dinámicas capaces de transformar causas colectivas en argumentos de verdad; y el secreto público, que permite la emergencia de un vínculo social a partir de un saber que instaura una frontera en torno a qué es lo que NO se debe saber. Se trata de la posibilidad de establecer vínculos sociales (alterados) en Estados 
en los cuales el poder se presenta a menudo de manera difusa y amenazadora.

El Diccionario de la lengua española da una acepción más de qué puede entenderse por frontera: "límite". Hay en la disciplina antropológica diversas aproximaciones que nos permitirían dar cuenta de una epistemología en esencia diferente, basada en lo liminal. Desde los sistemas de clasificación primitivos de Durkheim y Mauss sabemos que la necesidad de clasificar y de distinguir es la que hace posible establecer las coordenadas sociales de la realidad. No clasificamos lo que ya está dado, más bien, a partir de la clasificación lo contemplamos como tal. Esta necesidad de establecer fronteras y límites no opera sólo en un registro intelectual, sino también práctico. Turner explora cómo los atributos de la liminalidad, y por consecuencia los de los sujetos liminales, son por fuerza ambiguos, porque en este estado escapan del sistema de clasificación que, por lo común, los coloca en una determinada situación o posición en el espacio social. Los sujetos liminales no están ni en un sitio ni en otro (Turner, 1988).

Lo relevante de estos momentos de transición es que, aunque la liminalidad en sentido estricto sea breve, a menudo se imbrica en una liminalidad prolongada en donde la transición no se logra de una vez por todas, sino a través de ciertas minitransiciones que se caracterizan porque han de ser repetidas en múltiples registros. En efecto, hay que recordar que el sujeto no puede estar nunca plenamente determinado por el orden social, porque lo social no es lo que está ahí desde siempre manteniendo a los sujetos unidos. Más bien emerge al reensamblarse en el seno de prácticas y discursos que se repiten. Las fronteras que establece una comunidad alterada a partir de las teorías de la conspiración funcionan por la repetición de discursos, gestos, teorías y rumores. Ahora bien, la repetición es la que garantiza la estabilidad, pero la que, al mismo tiempo, y por la necesidad que hay de su existencia, pone en evidencia la no totalización, la presencia de las fisuras y los intersticios: "Cualquier esfuerzo de interpelación o de constitución discursiva está sujeto a error, está acosado por la contingencia, puesto que el discurso mismo invariablemente fracasa en su intento de totalizar el campo social" (Butler, 2002: 136). La repetición asegura la interacción entre los miembros que se repiten los unos a los otros, pero, además, como en toda repetición hay desvíos-las cosas se repiten en espacios y en tiempos diferentes-; ello permite los matices, la necesidad de precisar o aclarar e incluso la de aportar algún detalle, lo cual -una vez más- exige formas de interacción y de vinculación social -alterada- en torno a la hipótesis misma de la conspiración. El secreto público permite, de igual modo, la emergencia de una comunidad alterada justamente porque lo que NO se debe saber se transmite en el registro de las prácticas y -al no articularse de manera por completo fija- puede desplazarse para admitir diversidad en éstas según los requerimientos de lo que, siguiendo a Taussig, hemos referido como cultura del terror. La posibilidad de establecer dicha vinculación-que si bien alterada sigue siendo social-es precisamente lo que está en juego en ese otro estado alterado que es la psicosis, en la que la frontera que supone la certeza delirante y el secreto de lo privado no puede ser compartida bajo el riesgo de vulnerar el meollo mismo del sujeto.

\section{Fuentes}

Abrams, Philip

1998 "Notes on The Difficulty of Studying the State", en Journal of Historical Sociology, año 1, núm. 1 , pp. 58-89.

Álvarez, José María

1996 "Límites de la concepción fenomenológica del delirio", en Revista de la Asociación Española de Neuropsiquiatría, año XVI, núm. 58, pp. 257-276.

AretXagA, BegoñA

2005 States of Terror, University of Nevada, Reno, $325 \mathrm{pp}$.

AretXagA, Begoña

2008 "Madness and the Politically Real: Reflections on Violence in Postdictatorial Spain", en Mary-Jo DelVecchio Good et al., Postcolonial Disorders, University of California Press, Berkeley, pp. 43-61.

Aulagnier, Piera

1991 "Le droit au secret: condition pour pouvoir penser", en Un interprete en quete de sens, Payot, París, pp. 219-238.

Bolaños, Claudia

Y SARA PANTOJA

2011 "CDHDF exige explicación sobre acciones de militares en la ciudad", en El Universal, 27 de enero <http://www.eluniversal.com.mx/

BROWN, WENDY nacion / 183278.html> [27 de octubre de 2013].

1995 States of Injury: Power and Freedom in Late Modernity, Princeton University Press, Nueva Jersey, 219 pp.

ButLER, JUDITH

2001 Mecanismos psíquicos de poder, Cátedra, Madrid, 213 pp.

Butler, Judith

2002 Cuerpos que importan. Sobre los límites discursivos del sexo, Paidós, México, 345 pp.

Colina, Fernando

2013 Sobre la locura, Cuatro Ediciones, Valladolid, 150 pp.

DÁvila, Guillermo

1925 "Estudio clínico de la esquizofrenia en sus diferentes formas", tesis de la Facultad de Medicina, Universidad Nacional de México, México, 205 pp. 
DERRIDA, JACQUES

2005 Canallas: Dos ensayos sobre la razón, Trotta, Madrid, 192 pp.

Gómez, Francisco

2011 "Marinos buscan a zetas en el DF", en El Universal, 26 de enero <http: / www.eluniversal. com. $\mathrm{mx} /$ nacion / 183240.html $>$ [27 de octubre de 2013].

GonzÁlez Rodríguez, Sergio

2009 El hombre sin cabeza, Anagrama, México, $186 \mathrm{pp}$

Gupta, AkHIL

1995 "Blurred Boundaries: the Discourse of Corruption, the Culture of Politics and the Imagined State”, en American Ethnologist, año 22, núm. 2, pp. 375-402.

HERMAN, Judith

1992 Trauma and Recovery, Basic Books, Nueva York, $290 \mathrm{pp}$.

LÉvi-Strauss, Claude

1995 "El hechicero y su magia", en Antropología estructural, Paidós, Barcelona, pp. 195-210.

Martínez, Fernando

2011 "Mondragón niega militarización en DF", en $E l$ Universal, 27 de enero < http: / www.eluniversal. com.mx/notas / 740563.html [27 de octubre de 2013].

NANCY, JEAN-LUC

2001 La comunidad desobrada, Arena, Madrid, 208

POPPER, KARL

2000 La sociedad abierta y sus enemigos, Paidós,

SANTNER, ERIC L. Barcelona, 704 pp.

2011 The RoyalRemains: The People's Two Bodies and the Endgames of Sovereignity, The University of Chicago Press, Chicago, 259 pp.
SASs, Louis A.

1994 Madness and Modernism: Insanity in the Light of Modern Art, Literature and Thought, Harvard University Press, Cambridge, 595 pp.

SCARry, Elaine

1985 The Body in Pain: The Making and Unmaking of the World, Oxford University Press, Nueva York, $385 \mathrm{pp}$.

Stevenson, Matilda Coxe

1904 The Zuni Indians: Their Mythology, Esoteric Fraternities and Ceremonies, Bureau of American Ethnology, Washington, D. C., 634 pp.

TAussig, Michael

1987 Shamanism, Colonialism, and the Wild Man: A Study in Terror and Healing, University of Chicago Press, Chicago, 517 pp.

TAussig, Michael

1997 The Magic of State, Routledge, Nueva York y Londres, $204 \mathrm{pp}$.

Taussig, Michael

1999 Defacement: Public Secrecy and the Labor of the Negative, Stanford University Press, Stanford, $311 \mathrm{pp}$.

TURNER, VICTOR

1988 El proceso ritual. Estructura y antiestructura, Taurus, Madrid, 223 pp.

WitTGenstein, LUDWIG

1988 Investigaciones filosóficas, Instituto de Investigaciones Filosóficas-Universidad Nacional Autónoma de México/Crítica, Barcelona, 547 pp.

YébenEs, ZENIA

2014 Los espíritus y sus mundos. Locura y subjetividad en el México moderno y contemporáneo, Universidad Autónoma Metropolitana/Gedisa, México, 505 pp.

ŽIŽEK, SLAVOJ

2007 El acoso de las fantasías, Siglo xxi Editores, México, $266 \mathrm{pp}$. 